\title{
METEOR STIP MARUNDA
}

JURNAL ILMIAH NASIONAL

SEKOLAH TINGGI ILMU PELAYARAN JAKARTA

Upaya Penanganan Kebocoran Butterfly Valve Pada Tangki Muat Di Kapal MT. Griya Ambon

Agus Widodo, Fausil, Hapsari Siwi Radityawati

Prodi Nautika

Sekolah Tinggi Ilmu Pelayaran

Jl. Marunda Makmur No.1 Cilincing, Jakarta Utara, Jakarta 14150

disubmit pada :2/7/20 direvisi pada : 10/10/20 diterima pada:15/11/20

\begin{abstract}
Abstrak
Setiap peralatan - peralatan yang digunakan dalam industri-industri tidaklah selalu dalam keadaan baik. Namun pada sewaktu-waktu akan mengalami kerusakan atau tidak berfungsi secara maksimal. Pemilihan jenis katup, bentuk desain dan jenis material memiliki peran yang sangat penting dalam kinerja dan kehandalan system butterfly valve agar valve menjadi tahan lama. Pada kapal MT. Griya Ambon standar pemakaian butterfly valve dengan merk Lokit Polymere telah mengalami kebocoran pada tangki muat no 1 kanan sebelum masa pemakaiannya berakhir atau before sale (masa garansi habis) kekuatan dari Butterfly valve ini sesuai standar makernya akan bertahan selama 5 tahun, tetapi pada kenyataannya pada tangki muat no 1 kanan mengalami kebocoran sebelum 5 tahun, dihitung dari kapal melakukan doking pada tahun 2016 dan mengalami kebocoran pada tahun 2018. Valve pada pipa yang berada di dalam tanki no 1 starboard terindikasi adanya kebocoran dan tidak kedap, sehingga muatan yang seharusnya masuk ke tanki no 3 port dan starboard ikut terisi ke tanki no 1 starboard, Jika hal ini dibiarkan berlanjut akan menimbulkan bahaya-bahaya loading dan akan menghambat proses loading karena dibutuhkan perbaikan, terlebih lagi jika kegiatan loading tidak terpantau dengan baik disaat ada kebocoran valve.
\end{abstract}

Copyright (C) 2020, METEOR STIP MARUNDA, ISSN : 1979-4746

Kata kunci : butterfly valve, kebocoran, tangki muat, tanker

Permalink/DOI : https://doi.org/10.36101/msm.v13i2.146 


\section{PENDAHULUAN}

\section{A. LATAR BELAKANG}

Dalam dunia maritime Indonesia mempunyai peran penting dalam hal angkutantransportasi laut untuk menunjang kehidupan ekonomi masyarakat. Pengangkutan muatan dalam hal transportasi laut dan antarmengantar barang mulai dari antar pulau antar daerah maupun antar Negara seperti ekspor dan impor yaitu dengan menggunakan kapal. Kapal laut merupakan salah satu modal transportasi yang sangat efisien dan mudah digunakan karena bisa mengangkut barang dengan jumlah yang banyak dan dalam satu kali pelayaran. Dengan perbedaan jenis muatan yang harus diangkut dan berapa banyak yang harus dimuat, maka timbulah jenis kapal yang berbeda-beda sesuai kebutuhan dan kemajuan ekonomi. Kapal tanker merupakan salah satu sarana transportasi laut yang memuat minyak dari pelabuhan muat sampai ke pelabuhan bongkar. Dalam hal ini kapal tanker yang di maksud adalah jenis product oil tanker yaitu minyak yang di peroleh dari hasil penyulingan seperti HOMC, Naptha, Premium, Pertamax, dan lain-lain. Muatan berbahaya seperti minyak harus di muat secara hati-hati dan penuh konsentrasi, peralatan yang menunjang kegiatan loading harus dalam kondisi yang baik agar kegiatan loading berjalan dengan lancar dan tidak menimbulkan bahaya-bahaya loading. Peralatan yang ada di atas kapal harus menunjang halhal yang berkaitan tentang cargo terutama yang berhubungan dengan kegiatan loading harus selalu terpantau kondisinya, terlebih perangkat yang mengontrol masuk dan berhentinya muatan cair di dalam tanki melalui pipa yaitu valve yang harus kedap akan minyak. Sistem pipa yang terdapat pada kepal terutama valve yang ada pada jalur loading (cargo line) dan tanki-tanki, harus kedap dan berfungsi dengan baik. Jika valve ditemukan terdapat kebocoran maka muatan bisa tak terpantau dan mengakibatkan terhambatnya proses loading. Kerusakan butterfly valve menyebabkan tidak berfungsinya dengan baik proses bongkar muat berlangsung sehingga pemasangan butterfly valve yang tidak pada posisinya juga mengakibatkan kebocoran pada tanki muat. Pemakaian yang terusmenerus berlangsung menyebabkan valve terlalu cepat bergerak saat mesin beroprasi sehingga tinggi kemungkinan valve untuk rusak, valve juga bisa aus karena sering digunakan. Valve yang sudah rusak harus ditangani dan diperbaiki. Dibutuhkan pengawasan dari perwira dan ABK saat penanganan valve dalam proses perbaikan. Perbaikan saat proses loading berlangsung dapat menghambat seluruh jadwal kegiatan kapal dan dapat merugikan pihak-pihak yang bersangkutan, upaya penanganan ini dilakukan agar hal ini tidak terus berlanjut dan akan merugikan pihak perusahaan pelayaran, pihak chartering, maupun pihak kapal. Kapal yang sudah lama digunakan untuk berlayar atau bisa disebut kapal tua, yang artinya kondisi peralatan yang ada diatas kapal sudah sering dipergunakan dan sudah termakan usia, terlebih untuk kapal MT. Griya Ambon yang sudah berumur 21 tahun juga bisa berpengaruh pada kebocoran yang disebabkan oleh rusaknya valve yang bertipe butterfly. Pengoprasian cargo opration di dalam 
cargo control room (CCR) juga harus diperhatikan karena pengoprasian yang salah dapat merusak valve itu sendiri. Valve yang terlalu sering terkena muatan cair berbahaya juga dapat merusak komponen yang ada pada valve itu sendiri. Oleh karena itu penanganan perbaikan dalam hal kerusakan valve harus dilaksanakan agar semua pihak tidak mendapat kerugian terlebih lagi di kapal MT. Griya Ambon yang merupakan kapal milik perusahaan PT. Humpuss Transportasi Kimia. Setiap peralatan - peralatan yang digunakan dalam industri-industri tidaklah selalu dalam keadaan baik. Namun pada sewaktu- waktu akan mengalami kerusakan atau tidak berfungsi secara maksimal. Pemilihan jenis katup, bentuk desain dan jenis material memiliki peran yang sangat penting dalam kinerja dan kehandalan system butterfly valve agar valve menjadi tahan lama. Pada kapal MT. Griya Ambon standar pemakaian butterfly valve dengan merk Lokit Polymere telah mengalami kebocoran pada tangki muat no 1 kanan sebelum masa pemakaiannya berakhir atau before sale (masa garansi habis) kekuatan dari Butterfly valve ini sesuai standar makernya akan bertahan selama 5 tahun, tetapi pada kenyataannya pada tangki muat no 1 kanan mengalami kebocoran sebelum 5 tahun, dihitung dari kapal melakukan doking pada tahun 2016 dan mengalami kebocoran pada tahun 2018. Kamis, 27 Desember 2018 kapal sedang melaksanakan proses loading di Balikpapan dengan mengangkut muatan Naptha yang akan di bawa ke Balongan untuk dibongkar. Saat proses kegiatan loading Naptha berlangsung, perwira jaga melakukan line up loading sesuai loading plan yang sudah direncanakan oleh Chief Officer, maka semua drop line pipe atau jalan masuk minyak yang posisinya berada di atas deck atau bisa disebut di cargo line dalam posisi terbuka untuk menghindari kelalaian awak kapal dalam membuka dan menutup valve drop line, kemudian valve yang berada di dalam pipa tanki minyak dalam kondisi tertutup kecuali pada tanki yang akan di muat. Pada saat loading tanki no 3 port dan starboard dengan ullage (jarak permukaan minyak ke top deck) setinggi $5 \mathrm{~m}$, perwira jaga dan ABK memantau kegiatan proses loading di cargo control room (CCR), tepatnya di layar saab radar (alat pemantau muatan). Terlihat di saab radar bahwa muatan pada tanki no 1 starboard telah terisi muatan dengan ullage 4 meter tingginya. Melihat hal ini chief officer mengambil tindakan untuk menutup drop line valve yang terbuka pada tanki 1 port dan starboard. Setelah drop line tanki 1 port dan starboard tertutup maka chief officer memantau pergerakan minyak yang ada pada tanki no 1 starboard di layar saab radar, setelah di pantau oleh perwira jaga, ullage pada tanki muatan tidak mengalami perubahan. Valve pada pipa yang berada di dalam tanki no 1 starboard terindikasi adanya kebocoran dan tidak kedap, sehingga muatan yang seharusnya masuk ke tanki no 3 port dan starboard ikut terisi ke tanki no 1 starboard. Jika hal ini dibiarkan berlanjut akan menimbulkan bahaya- bahaya loading dan akan menghambat proses loading karena dibutuhkan perbaikan, terlebih lagi jika kegiatan loading tidak terpantau dengan baik disaat ada kebocoran valve. Oleh karena latar belakang yang ada di atas maka

penulis tertarik untuk mengangkat masalah yang akan di angkat dalam penulisan skripsi dengan judul sebagai berikut:

“Upaya Penanganan Kebocoran Butterfly Valve pada Tangki Muat Di Kapal MT 


\section{Griya Ambon”}

\section{B. RUMUSAN MASALAH}

Dari pembahasan masalah di atas, dengan demikian dapat diambil rumusan masalah sebagai berikut :

1. Bagaimana cara menangani kerusakan pada butterfly valve di tanki no starboard?

2. Bagaimana cara meningkatkan keterampilan perwira jaga dan $\mathrm{ABK}$ dalam

pengoprasian loading di cargo control room(CCR)

\section{TUJUAN DAN MANFAAT PENULISAN SKRIPSI}

1. Tujuan penyusunan skripsi ini ialah sebagai berikut

a) Untuk mengetahui solusi dan penyebab terkait permasalahan rusaknya

butterfly valve pada tanki no 1 starboard

b) Untuk menemukan solusi terkait masalah kurangnya keterampilan perwira jaga dan ABK dalam pengoprasian loading di cargo control room (CCR)

2. Manfaat Penyusunan Skripsi

a) Teoritis

Menambah wawasan dan ilmu pengetahuan yang dapat menjadi referensi taruna, dosen, perwira, anak buah kapal, serta perusahaan pelayaran dalam menangani kerusakan yang terjadi pada butterfly valve pada tanki no 1 starboard sehingga kebocoran dapat tertangani.

b) Praktisi
Sebagai masukan untuk kapal penulis yaitu MT. Griya Ambon dalam menangani kerusakan pada butterfly valve tanki no 1 starboard, serta mengatasi kurangnya keterampilan perwira jaga dan ABK pada saat proses loading di cargo control room (CCR) agar kebocoran pada butterfly valve dalam tanki bisa tertangani.

3. METODE

\subsection{WAKTU DAN TEMPAT PENELITIAN}

\subsubsection{Waktu Penelitian}

Dalam mendapatkan data dan informasi yang lebih terperinci diperoleh pada saat menulis menjalani praktek laut tanggal 27 July 2018 sampai dengan turun kapal dan selesai kontrak pada tanggal 21 Agustus 2019. Selama menjalani praktek kerja nyata (prala) dengan posisi cadet deck (deck apprentice) di MT. Griya Ambon

\subsubsection{Tempat Penelitian}

Tempat penulis melaksanakan penelitian yaitu di atas kapal MT. Griya Ambon yang dimiliki oleh perusahaan PT. Humpuss Transportasi Kimia yang berkebangsaan Indonesia.

\subsection{METODE PENDEKATAN DAN TEKNIK PEMGUMPULAN DATA}

\subsubsection{Metode Pendekatan}




\subsubsection{Teknik Pengumpulan Data}

Melalui pengkajian fakta-fakta dari pengamatan dan pengetahuan yang dipadukan di lapangan agar dapat menjadi prinsip dan data yang jelas, maka data dan infromasi tersebut harus lengkap, objektif dan berhubungan dalam penyusunan penulisan. Oleh karena itu, digunakanlah teknik pengumpulan data yang berupa :

\section{a. Metode Riset Perpustakaan}

Yaitu penelitian perpustakaan yang dilakukan oleh penulis dengan maksud memperoleh data sekunder yaitu data-data yang didapat dari membaca buku-buku literature maupun artikel yang berkaitan dengan kerusakan valve pada pipa dalam tangki agar tidak terjadi kebocoran muatan. Hal ini dimaksudkan untuk memperoleh konsep yang diperlukan dalam pembahasan.

\section{b. Observasi (Pengamatan Lapangan)}

Observasi merupakan bentuk penerimaan data yang dilakukan dengan cara merekam kejadian, menghitung, mengukur dan mencatat kegiatan yang dilakukan secara langsung. Teknik observasi merupakana teknik mengumpulkan data yang dilakukan secara sistematis, prosedur yang terstandar dan tujuannya memperoleh ukuran tentang variable serta melakukan pengukuran terhadap variabel. Setelah melakukan observasi secara langsung ke lapangan yaitu berdasarkan pengalaman dan pengamatan selama melaksanakan praktek laut saat berada di kapal MT. Griya Ambon selama satu tahun sebagai apperantice deck. Setelah melakukan pengamatan, penulis menemukan kesalahan yang tidak relevan yang dilakukan oleh perwira dan ABK dalam upaya penanganan kebocoran butterfly valve pada tanki, dimulai dari :

1) Kebocoran diduga dari kerusakan butterfly valve pada tanki no 1 starboard, penambahan muatan yang terlihat di saab radar semakin membuat yakin bahwa terdapat kerusakan pada butterfly valve yang ada di dalam tanki. Tekanan aliran minyak yang tinggi serta valve yang terlalu cepat bergerak saat mesin beroprasi bisa membuat seat pada valve menjadi tipis dan bolong, sehingga muatan cair bisa dengan mudahnya melewati valve melalui kerusakan tersebut. Kerusakan valve harus segera ditangani, agar tidak terjadi kebocoran yang berkelanjutan dan memberi dampak buruk kepada pihak kapal, crew, maupun perusahaan.

2) Kurang pengetahuan dan terampilnya perwira jaga dan ABK dalam pengoprasian alat- alat serta proses loading di cargo control room (CCR), seharusnya perwira dan ABK sudah mengetahui alat-alat apa saja yang ada di CCR dan bagaimana cara mengoprasikannya. Sehingga banyak perwira dan ABK yang salah mengoprasikan peralatan saat memuat dan bongkar yang ada dalam CCR, dan mengakibatkan peralatan tersebut cepat rusak dan todak beroprasi dengan baik serta kerja yang asal-asal an dari pihak perwira dan ABK itu sendiri.

\section{c. Teknik Wawancara}

Wawancara adalah salah satu teknik pengumpulan data dimanapeneliti melaksanakan tanya jawab langsung kepada pihak-pihak yang berkaitan dengan masalah yang diteliti. Disini digunakan tanya jawab bebas antara pewawancara dengan responden, pewawancara menggunakan tujuan penelitian sebagai pedoman sehingga informasi yang diinginkan tetap dapat diperoleh. Wawancara dilakukan secara perorangan antara seorang pewawancara yang berhadapan langsung 
dengan seorang responden

yang diwawancarai.

Responden yang diwawancara adalah : Nahkoda

Pertanyaan yang ditanyakan adalah pertanyaan yang berkisar seputar penanganan kerusakan butterfly valve yang ada pada tanki. Pertanyaan dengan responden terlampir dalam lampiran 3

\section{d. Dokumentasi}

Dokumentasi adalah teknik pengumpulan data yang dilakukan dengan cara mengumpulkan data dengan cara melihat dan mengabadikan serta mempelajari dokumen-dokumen yang ada kaitannya dengan pembahasan kajian ini untuk dijadikan sebagai bahan pendukung penelitian yang dilakukan. Dalam dokumentasi penulis membaca dokumendokumen yang berhubungan dengan obyek penelitian dengan maksud agar didapat data yang lengkap, dan dapat dipertanggungjawabkan,

Penulis juga mengumpulkan data berupa foto. Foto yang dilampirkan dalam skripsi ini didapatkan oleh penulis selama melaksanakan praktek laut dengan melakukan pengambilan foto yang sebenarnya terjadi di lapangan dan sebagian adalah gambar atau foto dari beberapa literatur dan internet yang penulis dapatkan. Dalam hal ini, melakukan pengambilan foto butterfly valve pada tanki pada saat dalam keadaan sebelum dan sesudah proses penanganan serta foto pelaksanaan kegiatan penanganan kerusakan butterfly valve yang terlampir pada lampiran 5 hingga lampiran 10.

\section{HASIL DAN PEMBAHASAN}

Berdasarkan data yang telah dipaparkan di atas, maka dapat dianalisis penyebab terjadinya kebocoran butterfly valve pada tangki muat yaitu

\section{Kerusakan pada butterfly valve}

a. Kerusakan ini meliputi muatan cair yang mengalir ke tanki yang tidak seharusnya karena valve rusak dan berlubang

b. Pengikisan seat O-ring butterfly valve karena terlalu lama dipergunakan

c. Terdapat lubang pada seat O-ring butterfly valve karena terkikis

d. Kemampuan kerja valve yang berkurang, kemampuan untuk kembali ke keadaan tertutup setelah posisi terbuka

e. Pihak Chief Officer tidak memperhatikan kondisi valve sebelum dimulainya proses memuat sehingga menyebabkan terjadinya hasil yang kurang optimal.

f. Adanya serangan korosi di bagian seat Oring butterfly valve

g. Valve yang terlalu cepat bergerak saat mesin beroperasi sehingga rusakSebagaimana diketahui bahwa tekanan pada tangki akan meningkat seiring meningkatnya temperatur tangki muatan. Hal ini dapat dijelaskan sesuai dengan hukum tekanan pada teori gas ideal. 
2. Kurangnya keterampilan perwira jaga dalam pengoprasian loading di cargo control romm (CCR)

a. Kerusakan alat komunikasi. Alat komunikasi sangat berguna sekali untuk berkomunikasi antara perwira jaga di cargo control room dengan juru mudi jaga dan kadet yang berada di atas tangki muatan. Apabila komunikasi tidak bisa berjalan lancar maka proses muat akan terhambat.

b. Terjadinya kesalahan dalam komunikasi antara perwira jaga di dalam cargo control room dengan juru mudi jaga dan kadet yang berada di atas tangki muatan sehingga proses muat tidak bisa berjalan dengan baik.

c. Kurangnya pengawasan dari para perwira jaga yang berada di dalam cargo control room sehingga tidak mengetahui apabila muatan luber atau mengalami kebocoran

d. Perwira jaga yang sudah selesai jam jaganya tidak melakukan serah terima tugas jaga dengan baik kepada perwira jaga berikutnya, sehingga perwira jaga pengganti tidak mengetahui apa yang sedang dilakukan pada saat jam jaga sebelumnya dan order-order apa yang telah diberikan oleh nahkoda, mualim I, maupun pihak darat.

e. Perwira jaga sering melakukan kesalahan pada saat mengoperasikan control panel sehingga dalam pengoperasian cargo control room tidak bisa berjalan dengan baik. Valve memiliki peranan yang sangat penting dalam pengoperasian cargo control room, sehingga apabila kita melakukan kesalahan dalam pengoprasian valve, maka dalam pengoperasian cargo control room tidak akan berjalan dengan baik.

f. Perwira jaga belum paham akan tugastugas yang harus dilakukan saat pengoprasian proses muat beserta alatalat yang ada di cargo control room (CCR)

\subsection{PEMECAHAN MASALAH}

Pemecahan masalah yang paling efektif untuk tiap masalah yang dialami penulis di atas kapal yaitu:

\section{1) Kerusakan pada butterfly valve}

Diadakan penanganan secara langsung ke dalam tangki muat agar kerusakan dari butterfly valve langsung tertangani.

a. Pra-Penanganan / Daftar Periksa penanganan butterfly valve

1) Pelaksanaan Proses Free Gas tangki muat

2) Persiapan membongkar butterfly valve

b. Penanganan butterfly valve

c. Pemeliharaan butterfly valve

2) Kurangnya keterampilan perwira jaga dalam pengoprasian loading di CCR

Diadakan pelatihan, pengarahan dan buku panduan dengan diberikan pengarahan melalui informasi tentang sistematika kerja perwira dan ABK dengan pengetahuan dan diharapkan dapat bekerja dan mengerti tugasnya. Dalam hal memberikan pengarahan atau informasi banyak cara kita untuk menyampaikannya, seperti:

a. Ceramah atau Diskusi

b. Melalui film dan poster-poster

c. Adanya buku latihan dan panduan

d.Diadakan safety meeting sebelum pelaksanaan penanganan kebocoran butterfly valve

e.Memperdalam keterampilan dalam pengoperasian Cargo Control Room

f. Memberikan pelatihan

\section{KESIMPULAN}

1. Faktor utama penyebab kebocoran butterfly valve

a. Kerusakan ini meliputi muatan cair yang mengalir ke tanki yang tidak 
seharusnya karena valve rusak dan berlubang

b. Pengikisan seat O-ring butterfly valve karena terlalu lama dipergunakan

c. Terdapat lubang pada seat O-ring butterfly valve karena terkikis

d. Kemampuan kerja valve yang berkurang, kemampuan untuk kembali ke keadaan tertutup setelah posisi terbuka

e. Pihak Chief Officer tidak memperhatikan kondisi valve sebelum dimulainya proses memuat sehingga menyebabkan terjadinya hasil yang kurang optimal.

f. Adanya serangan korosi di bagian seat valve

g. Valve yang terlalu cepat bergerak saat mesin beroperasi sehingga

2. Upaya penanganan kebocoran butterfly valve pada tangki muat

a. Perbaikan dengan mengganti valve berlubang dengan valve yang baru

b. Perawatan pada valve dengan cara :

1) Daily maintenance/daily work.

2) Pemeriksaan valve secara berkala.

3. Kurangnya pengalaman awak kapal, khususnya pada perwira dan ABK yang pertama kali naik ke kapal tanker. Perwira yang kurang terampil dalam mengoperasikan CCR dan melaksanakan prosedur serta kesalahpahaman dalam berkomunikasi. Dapat menghambat jalannya proses bongkar muat di atas kapal.

4. Kurang pedulinya crew kapal akan tujuan terhadap perawatan valve. Perawatan valve hanya berjalan sebagai rutinitas di kapal dan tidak terlaksananya perawatan secara optimal yang dapat mengakibatkan ketidaktahuan pihak kapal apabila terdapat kerusakan pada komponen pada valve.

\section{UCAPAN TERIMAKASIH}

Penyusunan skripsi ini didasarkan atas pengalaman dan penelitian yang penulis peroleh selama menjalani praktek laut di atas kapal MT. Griya Amon, serta pengetahuan yang diberikan oleh dosen pada saat pendidikan.

Pada kesempatan ini pula penulis ingin menyampaikan ucapan terima kasih kepada semua pihak yang telah membantu dalam menyelesaikan skripsi ini, antara lain :

1.Yth. Bapak Amirudin, M.M, selaku Ketua Sekolah Tinggi Ilmu Pelayaran Jakarta.

2. Yth. Ibu Suhartini, M.M.Tr, selaku Ketua Jurusan Nautika, Sekolah Tinggi Ilmu Pelayaran.

3. Yth. Bapak M. Yusuf, S.E., M.M. selaku Dosen Pembimbing 1, yang telah meluangkan waktu, tenaga, dan pikiran dalam membimbing dan memberikan penulis petunjuk dalam pengerjaan skripsi ini.

4.Yth. Bapak Capt. Fausil, M.A,M.Mar, selaku Dosen Pembimbing 2 yang telah memberikan pengarahan dalam penulisan skripsi ini.

5. Bapak dan Ibu dosen Sekolah Tinggi Ilmu Pelayaran Jakarta, baik yang secara langsung maupun tidak langsung yang telah memberikan bekal ilmu pengetahuan yang berguna bagi penulis dan telah banyak membantu kelancaran proses penulisan dan penyusunan skripsi ini.

6. Orangtua tersayang Bapak L. Suparyono dan Ibu Naomi Silaturochmi yang telah bekerja keras serta memberikan kasih sayang dan doanya kepada penulis untuk mampu bertahan sampai sekarang ini. Kakak-kakak saya tersayang Hapsara Soma Adhi Sasangka dan Ganesha Putra Vidya Hutama yang senantiasa memberikan dorongan, semangat, serta bantuan doa kepada penulis dalam menyelesaikan tugas akhir ini.

7.PT. HUMPUSS TRANSPORTASI KIMIA yang telah menyediakan tempat untuk penulis melaksanakan praktek laut.

8.Capt. A.J Nikijuluw, Chief Officer Nurul Mughni, Second Officer Reynaldi Jakadewa, Third Officer Gilank Gustisadhewa, dan Fourth Officer Dwi Laksana Putra serta seluruh crew di 
kapal MT. GRIYA AMBON.

9.Para Senior dan Junior di Sekolah Tinggi Ilmu Pelayaran.

10. Teman-teman Angkatan LIX (Angkatan 59) Sekolah Tinggi Ilmu Pelayaran Jakarta, khususnya teman-teman Kelas Nautika VIII A yang menjadi sumber motivasi dan ide, terutama Rezki Musdalifah Kwano dan Tabita Septiana Killansandra Silalahi.

11. Teman-teman kamar N-201, Ruth Westefien dan Kadek Yulita, serta kamar J-203, Grace Maria, Rika Desy, Karina Ananda, Rakhmah Zakiyah, serta teman-teman Taruni 59 yang tak pernah lelah memberikan motivasi, ide dan saran bagi penulis selama proses penyusunan skripsi.

12. Sahabat-sahabat terbaik saya M. Iksan Fatoni, Syaifian Alim, Widi Saputra, Dwi Darmawan,

Lina Oktavia, Khaizatunnusro, Luki Kusumaningtyas, dan Jein Kristin Irawati yang selalu menemani dan memberi semangat.

13.Dan semua pihak yang tidak dapat Penulis sebutkan satu per satu yang telah membantu penulis dalam menjalani Praktek Laut dan penyusunan skripsi ini

\section{DAFTAR PUSTAKA}

Muhammad Ngajenan, Kamus Etismologi Bahasa Indonesia, (Semarang: Dahara Prize 1990), Hal. 177

Peter Salim dan Yeni Salim, (2005) Kamus Besar Bahasa Indonesia, Jakarta: Modern English Press, hal, 1187.

Istopo. 1999. Kapal Dan Muatannya, edisi kedua, Koperasi Karyawan BP3IP, Jakarta.

MARPOL Consolidated Edition 2011, International Maritime Organization, London 2011.

Moekijat. 1997. Manajemen Sumber Daya Manusia, edisi keempat, penerbit CV. Pioner Jaya, Yogyakarta.

Nawawi, H, Hadari. 2008. Manajemen Sumber Daya Manusia, edisi keempat, penerbit Gajah Mada, Yogyakarta.

Oil Tanker Familarization. Badan DIKLAT Perhubungan, Jakarta 2000.STCW 1978 as amended in 1995 and 1997, International Maritime Organization, London 2001.

Verwey, A. 2011. Tank Cleaning Guide, penerbit Chemical Laboratories, Rotterdam.

Valve Handbook 3rd Edition, Authors: Philip Skousen, Published: May 2011

M\&H VALVE COMPANY. AWWA C504-00. CLASS 150, 200, \& 250. BUTTERFLY VALVES

Fisher Control International. (2001). Control Valve Handbook: Thord Edition. Fisher Control International, Inc. USA.

Valve Corporation. (2012). Valve:Handbook for New Employees. Valve Press. Bellevue, Wahington USA.

Regin. (2012). Valve Handbook. AB Regin. Kallered, Sweden.

International Safety Guide For Oil Tankers Terminals (ISSGOT), Fifth Edition, London 2006.

SMMK3L (Sistem Manajemen Mutu, Kesehatan, Keselamatan Kerja Dan Lingkungan), Standard Operasional Prosedur (SOP), PT. Humpuss Transportasi Kimia 2016

Jakarta, STIP, 2010, Pedoman Penyusunan Skripsi, STIP Jakarta, Jakarta. 